Bulletin of Pharmaceutical Sciences
Assiut University

\title{
PERFORMANCE OF QUERCETIN-CHITOSAN GELS AS TOPICAL DELIVERY SYSTEMS
}

\author{
Nermin E. ELeraky ${ }^{*}{ }^{*}$ Gihan Fetih $^{1,2}$ and Mahmoud El-Badry ${ }^{1,2}$ \\ ${ }^{1}$ Department of Pharmaceutics, Faculty of Pharmacy, Assiut University 71526, Assiut, Egypt \\ ${ }^{2}$ Assiut International Center of Nanomedicine, Al-Rajhy Liver Hospital, Assiut University, Assiut \\ 71515, Egypt
}

This study was designed to evaluate suitability of chitosan polymer as a vehicle for topical delivery system. Quercetin (QUT) is a natural flavonoid, was incorporated into the gel vehicles in a concentration of $0.5 \% \mathrm{w} / \mathrm{v}$. Gels were prepared with three different concentrations and different molecular weights of chitosan. Viscosity, drug release from prepared gels, permeation of drug through skin rat and anti-inflammatory activity of the drug using carrageenan induced rat paw edema method were studied. In-vitro release characteristics of the drug from different gels were carried out using dialysis membrane in phosphate buffer, $p H$ 5.5. The release data were treated with various kinetic principles to assess the relevant parameters. The general rank order of QUT release was $F 1>$ $F 4>F 2>F 3>F 5$. The results also showed that, the release of drug from the prepared gels obeyed the diffusion model (Higuchi's equation). The results revealed an inverse correlation between the drug release percent and the polymer concentration used. The permeation of drug through skin rat was carried out. The flux of drug is independent on the viscosity of the formulae. The results also showed a significant anti-inflammatory activity on rat paw edema.

\section{INTRODUCTION}

Quercetin (QUT, $3,3-, 4-, 5,7-$ pentahydroxyflavone), a plant flavonoid extracted and isolated from Sophora japonica L., is a common component of most edible fruits and vegetables and demonstrates a broad range of physiological activities, such as antiinflammatory, anti-proliferative effects on a wide range of human cancer cell lines, osteoporosis, and inhibition of glycolysis, macromolecule synthesis, pulmonary and cardiovascular diseases, and also against aging $^{1-3}$. Moreover, topical formulations of querectin mediated skin diseases like inflammation, pain and nociception, skin tumors, injury and wounds ${ }^{4}$ In recent years, QUT has gained much attention and arouses the enthusiasm of research work on cancer prevention and reduction of cardiovascular diseases. However, QUT has a very low oral bioavailability (16.2\%) due to its low solubility in water $(0.17-7.7 \mu \mathrm{g} / \mathrm{ml})$ and artificial gastric juice $(5.5 \mu \mathrm{g} / \mathrm{ml})$ and artificial intestinal juice
$(28.9 \mu \mathrm{g} / \mathrm{ml})^{5-8}$. So its application to skin has been shown to be a suitable delivery route for drugs formulated topically.

Chitosan, a polysaccharide derived from naturally abundant chitin, is currently receiving a great deal of attention for medical and pharmaceutical applications. The main reasons for this increasing interest are undoubtedly due to its appealing intrinsic properties. Indeed, chitosan is known for its biocompatibility allowing its use in various medical applications such as topical ocular application", implantation $^{10}$ or injection ${ }^{11}$. Moreover, chitosan is metabolized by certain human enzymes, e.g. Lysozyme, and can be considered as biodegradable ${ }^{12 \& 13}$. In addition, it has been reported that chitosan acts as a penetration enhancer ${ }^{14}$. Chitosan also promotes woundhealing ${ }^{15}$ and has bacteriostatic effects ${ }^{16}$. Finally, chitosan is abundant in nature, and its production is of low cost and is ecologically interesting $^{17}$. In Pharmaceutical applications, chitosan is used as a component in hydrogel. The main parameters influencing the

Received in 5/11/2019 \& Accepted in 14/11/2019 
characteristics of chitosan are its molecular weight (MW) and its degree of deacetylation ${ }^{15}$.

The aim of the present study is the preparation of quercetin (QUT) in different chitosan gel formulations; study of the effect of the concentration and molecular weight of the chitosan on the in-vitro release of the drug and permeation through skin rat. Also, study of the anti-inflammatory effect of the gel formulation activity on the paw edema in rats.

\section{MATERIALS AND METHODS}

\section{Materials}

Quercetin was kindly donated from (Searle, Augusta GA, USA). Chitosan with different molecular weights from (Fluka Chemie AG (Buchs, Switzerland), Semipermeable membrane (M.wt cutoff 12000 $\mathrm{kDa}$ ) (Cellulose tubing, Sigma diagnostics, St. Louis, MO, USA). All other chemical were of the analytical grade.

\section{Preparation of chitosan gels}

Chitosan gels were prepared at $1-3 \% \mathrm{w} / \mathrm{v}$ of the medium molecular weight, $2 \% \mathrm{w} / \mathrm{v}$ of low, medium and high molecular weight in lactic acid solution $(1.0 \% \mathrm{v} / \mathrm{v}) .0 .5 \% \mathrm{w} / \mathrm{v}$ of drug was dissolved in the least amount of propylene glycol and added to the chitosan gel. Methyl paraben sodium salt $(0.1 \%$, w/v) was added as a preservative. The contents were stirred and the resulting gel solutions were sonicated to remove the air bubbles. Each of the test samples were filled into 4-oz tubes till further use.

\section{Determination of gel viscosity}

Rheological experiments were performed to examine the viscous and elastic properties of the different formulations. Viscosity measurements of gels were performed on a Brookfield digital viscometer (Model DV-II+ Brookfield Engineering Laboratories, INC, Stoughtoon, USA) at room temperature.

\section{In-vitro release of Quercetin (QUT) from gel formulations}

In-vitro release of the drug from different gel formulations was evaluated using semipermeable membrane as reported by EL Maghraby et al. ${ }^{18}$. This employed the FDC-6 Transdermal Diffusion Cell Drive Console (Logan Instrument Corp., NJ. USA). The system is fitted with VTC-200 heater circulator with jacketed vertical glass Franz diffusion cells. The artificial membrane (Cellulose tubing, Sigma diagnostics, St. Louis, MO, USA) was mounted between the donor and acceptor compartments of the diffusion cell. The receptor compartment was $12 \mathrm{ml}$ and the cells have a diffusional area of $1.7 \mathrm{~cm}^{-1}$. The receptor cell was filled with phosphate buffer (pH 5.5). The system was adjusted at $37^{\circ} \mathrm{C} \pm$ 0.5 . A $0.5 \mathrm{gm}$ of the tested formulations was loaded into the donor compartment and occluded using a parafilm. Aliquots $(2.0 \mathrm{ml})$ were withdrawn at specific time intervals and replaced with fresh media. The samples were measured spectrophotometrically (UVspectrophotometer, Schmidzu-50-02, Kyoto, Japan) at maximum wave length $372 \mathrm{~nm}^{19}$ against blank similarly treated. The percent cumulative amount of drug released was calculated. All experiments were carried out in triplicate and the average values were calculated.

\section{Kinetic treatment of the release data}

The in-vitro release data of (QUT) from the investigated gel formulations was studied by curve fitting method to different kinetic models of zero-order, first-order and Higuchi models.

Zero-order release:

$$
\mathrm{M}_{\mathrm{t}} / \mathrm{M}_{\omega}=\mathrm{k}_{\mathrm{o}} \mathrm{t} \ldots \ldots \ldots \ldots \ldots \ldots \ldots . . \ldots \ldots \text { Eq. } 1
$$

$\mathrm{M}_{\mathrm{t}}$ : The cumulative amount of drug release at time t.

$\mathbf{M}_{\omega}$ : The cumulative amount of drug release at invintive time.

$\mathrm{k}_{\mathrm{o}}$ : zero-order release rate constant.

$\mathrm{t}$ : time.

First- order release:

$$
\operatorname{Ln}\left(1-\mathrm{M}_{\mathrm{t}} / \mathrm{M}_{\omega}\right)=-\mathrm{k}_{1} \mathrm{t} \ldots \ldots \ldots \ldots \ldots . . . \mathrm{Eq} .2
$$

$\mathrm{k} 1$ : first order release rate constant.

The Higuchi square root of time model has been derived from Fick's first law of diffusion and is suited for the modeling of drug release from a homogeneous planar matrix, assuming that the matrix does not dissolve:

$$
\left(\mathrm{M}_{\mathrm{t}} / \mathrm{M}_{\omega}\right)^{2}=\mathrm{kt} \text {.....................Eq.3 }
$$

The Korsmeyer-Peppas equation;

$$
\mathrm{M}_{\mathrm{t}} / \mathrm{M}_{\omega}=\mathrm{kt}^{\mathrm{n}} \ldots \ldots \ldots \ldots \ldots \ldots \ldots . . . . . . . . .4
$$

Korsmeyer-Peppas was used to study drug release mechanism by analyzing $\mathrm{n}$ as the 
diffusion exponent. According to equation (4) if $\mathrm{n} \leq 0.45$ the Fickian mechanism, $0.5 \leq \mathrm{n} \leq$ 0.8 the Non-Fickian and if $0.8 \leq \mathrm{n} \leq 1$ a zeroorder mechanism is governing the drug release mechanism from the gel ${ }^{20}$.

\section{Preparation of skin samples}

A skin permeation study of (QUT) gel formulations was carried out using full thickness rat $\operatorname{skin}^{21}$. To obtain the skin, Male Wister rats weighing 200-250 gm were used in this study. All experimental procedures were in accordance with the guidelines of the Animal Ethical Committee of Faculty of Pharmacy Assiut University. Rates were anesthetized using sodium pentobarbitone $60 \mathrm{mg} / \mathrm{kg}$ intraperitoneally. The abdominal skin was shaved using animal hair clipper, in the direction of tail to head. Dermis part of the skin was wiped three times with a wet cotton swab soaked in isopropanol to remove any adhering fat material. Then, the skin was kept in normal saline solution for two hours. The cleaned skin was washed with distilled water, wrapped in aluminum foil, and stored in a deep freezer at $20^{\circ} \mathrm{C}$ until further use.

\section{Skin permeation studies}

As mentioned in the in-vitro release experiments, skin permeation studies was carried out using FDC-6 Transdermal Diffusion Cell Drive Console (Logan Instrument Corp., NJ. USA). The skin was mounted with the stratum corneal side uppermost on the vertical glass diffusion cells. The mounted skin was equilibrated overnight. $0.5 \mathrm{gm}$ of the tested formulations was loaded on the skin surface into the donor compartment and occluded with parafilm. Samples were withdrawn periodically and replaced with fresh medium. These samples were analyzed for drug concentration. All experiments were carried out in triplicate and the average values were calculated.

\section{Data analysis}

The permeation profiles were conducted from the cumulative amounts of drug permeated against time. These profiles were used to calculate the flux of the drug, which was obtained from the slope of the regression line fitted to the linear portion of the curve. Lag time was calculated from the extrapolation of this line $\mathrm{x}$-axis.

\section{Anti-inflammatory activity of the prepared gels}

Acute inflammatory activity model, carrageenan induced rat paw edema method was applied in this study ${ }^{22 \& 23}$. Measurements of the in-vivo anti-inflammatory activity of the formulae conformed to guide lines of the Animal Ethics Committee of Faculty of Pharmacy Assiut University. The rats (36 rats) weighing about $200 \mathrm{gm}$ were divided into 6 groups each group has 6 rats. The animals of group 1 received placebo gel (chitosan gel without drug) and group 2, 3, 4, 5 and 6 received F1, F2, F3, F4 and F5 gel formulations respectively. Inflammation was produced in the rats using $0.1 \mathrm{ml}$ of $1.0 \% \mathrm{w} / \mathrm{v}$ carrageenan solution in saline. This was injected subcutaneously into left hind paw. To evaluate the topical anti-inflammatory activity of the gel formulations, paw edema was examined. Thirty minutes later, $0.5 \mathrm{~g}$ of each gel was applied topically on the edematous paw. The increase in the paw thickness was measured before carrageenan injection (time 0 ) and 2, 3, 4, 6 and 8 hrs after carrageenan administration using a dial micrometer. The percentage swelling of the paw and the percent inhibition of edema were calculated. The data were reported as mean $\pm \operatorname{SD}(n=6)$.

$$
\% \text { Swelling }=[(\mathrm{Vt}-\mathrm{Vi}) / \mathrm{Vi}] \times 100 \text {...Eq. } 5
$$

Where: $\mathrm{Vt}$ is the paw thickness at each time interval, and Vi the initial paw thickness before carrageenan injection. The average paw swelling in (QUT) treated rats were compared with that of control rats (which received placebo) and the percent inhibition of paw edema was estimates using the following equation:

$$
\begin{aligned}
& \% \text { Inhibition }=[1-(\% \text { swelling treated } / \% \\
& \text { swelling control)] x } 100 \text {....Eq. } 6 .
\end{aligned}
$$

\section{Statistical analysis}

Statistical analysis for the obtained results was carried out by the student t-test at 0.05 level of significances using (Microsoft office Excel 2007).

\section{RESULTS AND DISCUSSION}

Chitosan is a non-toxic, biocompatible and biodegradable polymer has been widely used for pharmaceutical and medical application. In 
this work, Chitosan was used as a gel forming agent to study the effect of chitosan concentration and its molecular weight on the release of (QUT) from different formulations. Visual inspection of freshly prepared formulae revealed smooth homogenous topical preparations with acceptable spread ability.

\section{Viscosity study}

It was seen from the flow curves (Figs. 1\& 2) that (QUT) containing chitosan gels exhibit psudoplastic flow and the viscosity increases significantly with increasing either the chitosan concentration (Fig. 1) or its molecular weight (Fig. 2). The viscosity of $3.0 \%$ (W/V) chitosan gel was found to be higher than that of $2.0 \%$ $(\mathrm{W} / \mathrm{V})$ and $1.0 \%(\mathrm{~W} / \mathrm{V})$. Also, the viscosity of $2.0 \%(\mathrm{~W} / \mathrm{V})$ chitosan gel prepared from (high molecular weight) was found to be higher than that of medium and low molecular weight (Table 1).

\section{In-vitro drug release study}

Drug release study from gel formulations is an important step during the development stages of topical formulation. To study the simultaneous effect of MW and the concentration of chitosan on the release profiles of (QUT), the percentage release of (QUT) from various chitosan gel formulations through four hours period was calculated (Fig. $3)$. Increasing the chitosan concentration of the medium molecular weight from $1.0 \%(\mathrm{~W} / \mathrm{V})$ to $3.0 \%(\mathrm{~W} / \mathrm{V})$ resulted in decreasing the percent of drug released $(\mathrm{p}<0.05)$. With $1.0 \%(\mathrm{~W} / \mathrm{V})$ gel formulation $78 \pm 3.2 \%$ of QUT was released. For $2.0 \%(\mathrm{~W} / \mathrm{V})$ chitosan gel, the percent release of drug was $68 \pm 1.3 \%$. Increasing the gel forming agent to $3.0 \%(\mathrm{~W} / \mathrm{V})$, the percentage of QUT was $54 \pm 1.2 \%$. The effect of chitosan molecular weight on the release of QUT from gel formulations was studied (Fig. 4). The concentration of gel forming agent was $2.0 \%$ was used. There is an inversely relationship between the molecular weight of chitosan used and the percent of drug release from prepared geles $(\mathrm{p}<0.05)$. For the high molecular weight grade the percent QUT released was $51 \pm 2.0 \%$. By using medium MW $65 \pm 1.3 \%$ was released. For Low MW the percent of drug released was $70 \pm 1.2 \%$.

Viscosity of the gel formulation may be a very important factor that affects release of drug since it may reduce diffusion rate of drug from the vehicles. Hereby, a reverse relationship was observed between the viscosity of chitosan gel and the percent of QUT released (Table 1). The gel formulation containing $1.0 \% \quad(\mathrm{~W} / \mathrm{V})$ chitosan medium molecular weight has the lowest viscosity $(10000 \pm 150 \mathrm{cP})$ and showed the highest percent of drug released (78 \pm 3.2$)$. While $2.0 \%$ (W/V) chitosan high molecular weight has the highest viscosity $(17150 \pm 250)$ showed the lowest percent of drug release $(51 \pm 2.0)$. These results were in agreement with EL-Maghraby G. $\mathrm{M}^{18}$ who reported that the release rate of hydrocortisone is dependent on the viscosity of the microemulsion formulations.

Release kinetic models were shown in table 2. As this table indicates, the correlation coefficient of the release data was fitted to Higuchi model which is higher than the other models and in all chitosan gel formulations, the diffusion exponent of Peppas equation is less than 0.5 which indicates a Fickian mechanism is dominant and controls the drug release from chitosan gels.

\section{Drug permeation through rat skin}

In-vivo measurement of drug administrated transdermally is a complex process. Due to lack of availability of human skin, the in-vitro drug permeation through skin was introduced as an alternative way to measure drug permeation. The Wister rat skin model has been used extensively, in view of the fact that its stratum corneum thickness, as well as water permeability, is close to that of human $\operatorname{skin}^{24}$.

In this study, drug permeation prior to steady state was similar for all gel formulations during the first hour, as shown in figures 5 and 6. After that, the permeation was changed according to the content of gel formulations. From table 3, it was observed that, the lag time for all formulae was between $0.53-0.78 \mathrm{hr}$. The flux of QUT during the steady state of formula F3 was significantly higher than that of F2 and F1, that may be according to the viscosity of each formula. That mean, there was an inversely relationship between the viscosity of the gel formulation and the flux of QUT. Also the flux of QUT of F3 was higher than that of F4 and F5. 


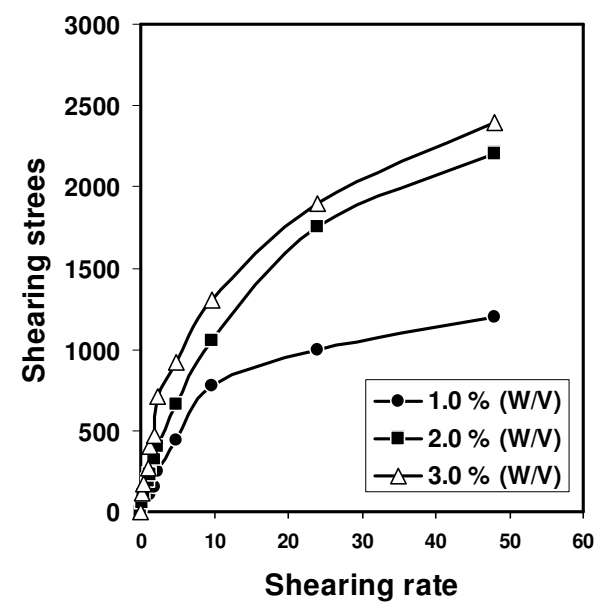

Fig. 1: Flow curves of chitosan gels prepared with different concentration of medium molecular weight chitosan.

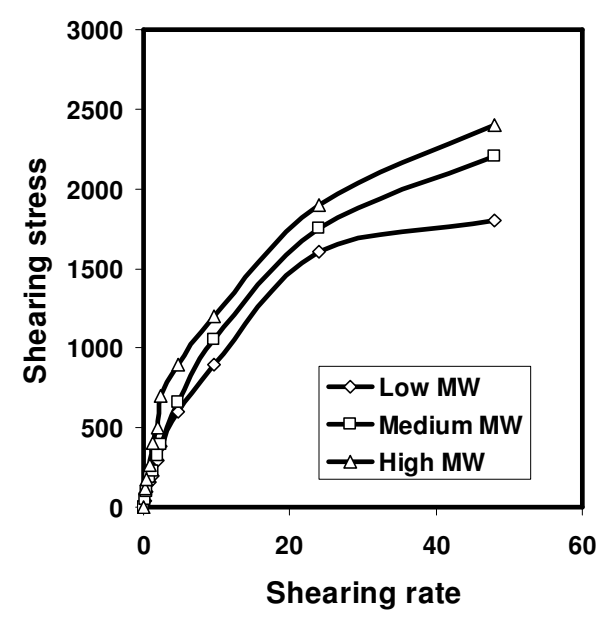

Fig. 2: Flow curves of chitosan gels prepared with $2.0 \%(\mathrm{~W} / \mathrm{V})$ of different molecular weight chitosan.

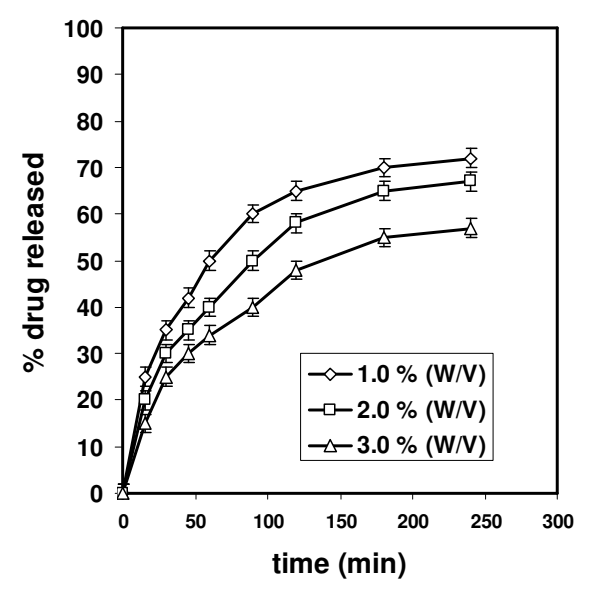

Fig. 3: Release profiles of QUT from chitosan gels prepared with different concentration of medium molecular weight chitosan.

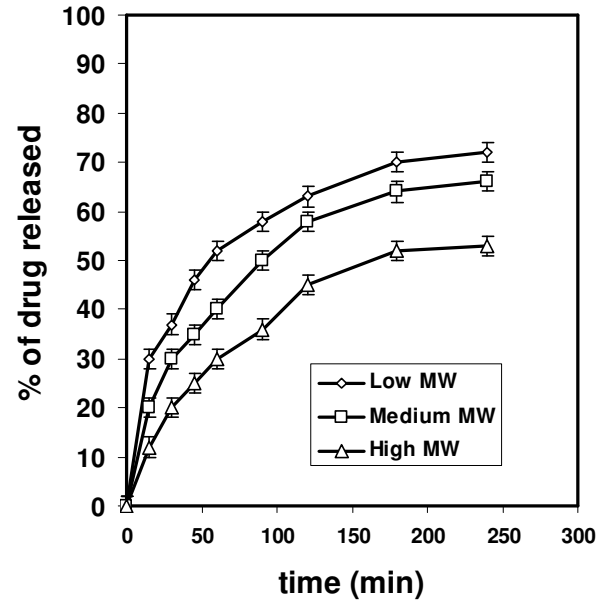

Fig. 4: Release profiles of QUT from chitosan gels prepared with $2.0 \%(\mathrm{~W} / \mathrm{V})$ of different molecular weight chitosan.

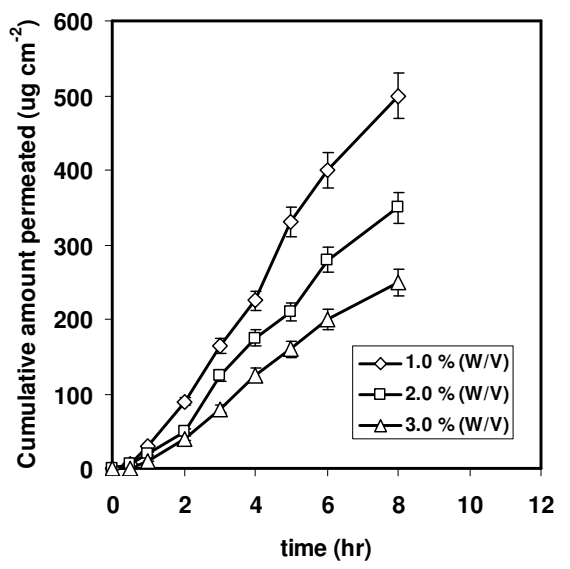

Fig. 5: Permeation profiles of QUT obtained after application of chitosan gels prepared with different concentration of medium molecular weight chitosan.

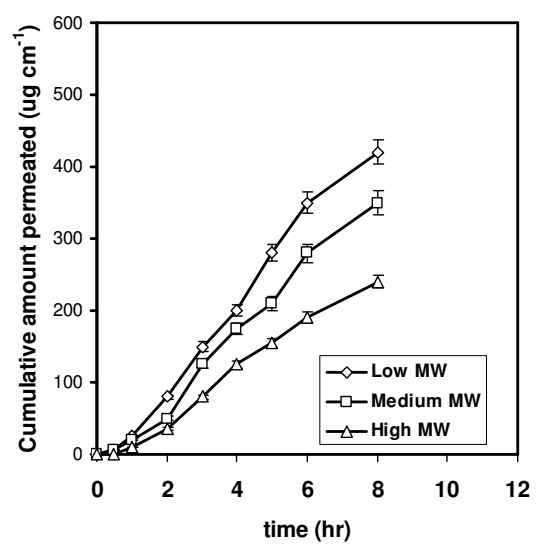

Fig. 6: Permeation profiles of QUT obtained after application of chitosan gels prepared with $2.0 \%(\mathrm{~W} / \mathrm{V})$ of different molecular weight chitosan. 
Table 1: Relationship between the viscosities (cP) of the prepared chitosan gel formulations and the percent of (QUT) released after $4 \mathrm{hrs}$.

\begin{tabular}{|c|c|c|c|}
\hline $\begin{array}{c}\text { Formulation } \\
\text { code }\end{array}$ & Content & Viscosity (cp) & $\begin{array}{c}\text { Percent of QUT released } \\
\text { after 4 hrs }\end{array}$ \\
\hline F1 & $1.0 \%$ MMW & $10000 \pm 150$ & $78 \pm 3.2$ \\
\hline F2 & $2.0 \%$ MMW & $13700 \pm 220$ & $68 \pm 1.3$ \\
\hline F3 & $3.0 \%$ MMW & $15250 \pm 320$ & $54 \pm 1.2$ \\
\hline F4 & $2.0 \%$ LMW & $11500 \pm 200$ & $70 \pm 1.2$ \\
\hline F5 & $2.0 \%$ HMW & $17150 \pm 250$ & $51 \pm 2.0$ \\
\hline
\end{tabular}

MMW : medium molecular weight. LMW : low molecular weight. HMW: high molecular weight.

Table 2: Kinetic models of (QUT) release from different chitosan gels.

\begin{tabular}{|c|c|c|c|c||}
\hline Gel form & $\begin{array}{c}\text { Zero-order } \\
(\mathrm{r})\end{array}$ & $\begin{array}{c}\text { First-order } \\
(\mathrm{r})\end{array}$ & $\begin{array}{c}\text { Higuchi model } \\
(\mathrm{r})\end{array}$ & $\mathrm{n}$ \\
\hline F1 & $0.846 \pm 0.025$ & $0.939 \pm 0.015$ & $0.980 \pm 0.011$ & $0.44 \pm 0.02$ \\
\hline F2 & $0.910 \pm 0.003$ & $0.950 \pm 0.010$ & $0.977 \pm 0.002$ & $0.45 \pm 0.03$ \\
\hline F3 & $0.919 \pm 0.010$ & $0.940 \pm 0.023$ & $0.981 \pm 0.001$ & $0.48 \pm 0.01$ \\
\hline F4 & $0.891 \pm 0.015$ & $0.940 \pm 0.025$ & $0.974 \pm 0.002$ & $0.44 \pm 0.02$ \\
\hline F5 & $0.915 \pm 0.010$ & $0.963 \pm 0.021$ & $0.982 \pm 0.004$ & $0.45 \pm 0.03$ \\
\hline
\end{tabular}

$-r$ : correlation coefficient

- $\mathrm{n}$ : Release exponent of Korsmeyer - Peppas equation.

Table 3: The permeation parameters of (QUT) obtained from different gel formulations.

\begin{tabular}{||c|c|c||}
\hline \hline Formulation code & Flux $\left(\mu \mathrm{g} \mathrm{cm}^{-2} \mathrm{~h}^{-1}\right)$ & Lag time $(\mathrm{h})$ \\
\hline F1 & $35.75 \pm 0.35$ & $0.78 \pm 0.05$ \\
\hline F2 & $48.35 \pm 2.15$ & $0.56 \pm 0.03$ \\
\hline F3 & $69.38 \pm 3.25$ & $0.53 \pm 0.02$ \\
\hline F4 & $34.30 \pm 1.12$ & $0.73 \pm 0.13$ \\
\hline F5 & $59.10 \pm 2.50$ & $0.66 \pm 0.09$ \\
\hline
\end{tabular}

Table 4: Anti-inflammatory activity of (QUT) in different gel formulations.

\begin{tabular}{|c|c|c|c|c|c|c|}
\hline \multirow{2}{*}{$\begin{array}{c}\text { Rat group } \\
\text { no }\end{array}$} & \multirow{2}{*}{$\begin{array}{c}\text { Gel } \\
\text { Formulation }\end{array}$} & \multicolumn{5}{|c|}{ \% \% Swelling of induced edema } \\
\hline & & $2 \mathrm{~h}$ & $3 \mathrm{~h}$ & $4 \mathrm{~h}$ & $6 \mathrm{~h}$ & $8 \mathrm{~h}$ \\
\hline 1 & Control & $\begin{array}{c}95 \pm 0.5^{*} \\
(5.00)\end{array}$ & $\begin{array}{c}94.0 \pm 0.5 \\
(6.0)\end{array}$ & $\begin{array}{c}93.0 \pm 1.0 \\
(7.2)\end{array}$ & $\begin{array}{c}91.0 \pm 0.6 \\
(9.2)\end{array}$ & $\begin{array}{c}90 \pm 0.5 \\
(10.0)\end{array}$ \\
\hline 2 & F1 & $\begin{array}{c}54.0 \pm 0.5 \\
(46.1)\end{array}$ & $\begin{array}{c}40.1 \pm 0.6 \\
(59.4)\end{array}$ & $\begin{array}{c}33.5 \pm 0.5 \\
(65.6)\end{array}$ & $\begin{array}{c}30.3 \pm 0.4 \\
(69.5)\end{array}$ & $\begin{array}{c}21.5 \pm 0.3 \\
(79.5)\end{array}$ \\
\hline 3 & $\mathrm{~F} 2$ & $\begin{array}{c}65.1 \pm 0.4 \\
(35.9)\end{array}$ & $\begin{array}{c}60.2 \pm 2.0 \\
(39.9)\end{array}$ & $\begin{array}{c}50.2 \pm 1.5 \\
(50.2)\end{array}$ & $\begin{array}{c}45.3 \pm 0.9 \\
(55.5)\end{array}$ & $\begin{array}{c}40.5 \pm 2.5 \\
(59.5)\end{array}$ \\
\hline 4 & F3 & $\begin{array}{c}61.2 \pm 0.8 \\
(39.0) \\
\end{array}$ & $\begin{array}{c}54.3 \pm 0.5 \\
(45.1) \\
\end{array}$ & $\begin{array}{c}51.2 \pm 0.7 \\
(49.5) \\
\end{array}$ & $\begin{array}{c}45.1 \pm 0.5 \\
(54.4)\end{array}$ & $\begin{array}{c}41.4 \pm 1.5 \\
\quad(58.6) \\
\end{array}$ \\
\hline 5 & $\mathrm{~F} 4$ & $\begin{array}{c}56.1 \pm 0.4 \\
(44.9) \\
\end{array}$ & $\begin{array}{c}51.5 \pm 2.0 \\
(47.9)\end{array}$ & $\begin{array}{c}50.5 \pm 1.2 \\
(50.5)\end{array}$ & $\begin{array}{c}40.3 \pm 1.2 \\
(58.9)\end{array}$ & $\begin{array}{c}32.5 \pm 1.1 \\
(67.5)\end{array}$ \\
\hline 6 & F5 & $\begin{array}{c}74.2 \pm 0.3 \\
(25.8)\end{array}$ & $\begin{array}{c}65.3 \pm 0.2 \\
(34.5)\end{array}$ & $\begin{array}{c}58.4 \pm 1.1 \\
(42.3)\end{array}$ & $\begin{array}{c}52.6 \pm 1.3 \\
(48.5)\end{array}$ & $\begin{array}{c}47.8 \pm 0.9 \\
(51.3)\end{array}$ \\
\hline
\end{tabular}

*Mean \pm SD

- The value between parentheses indicates the \% inhibition of edema. 
Correlation of the skin permeation results with the release results indicated that, the release rate was greater than the permeation flux of QUT in all gel formulations. Hillton et al. ${ }^{25}$ has reported that, there are many factors that may influence the extent of percutaneous absorption of a drug. Partitioning of the chemical between the vehicle and the stratum corneum results in a concentration gradient developing across the skin, this is influenced by chemical-vehicle- skin interaction.

\section{Anti-inflammatory activity studies using paw edema}

Topical anti-inflammatory activity of semisolid preparations has been reported when applied 1 and $2 \mathrm{hrs}$ before carrageenan treatment as mentioned by Hiramatsu et $a l^{26}$. Clinically, it seems more reasonable to apply the anti-inflammatory topical preparations after the inflammation stimulus ${ }^{23}$. Table 4 illustrates the anti-inflammatory activity of different gel formulations on the hind paw of the rats. It was shown that, all the gel formulations have significant effect $(\mathrm{p}<0.05)$ as antiinflammatory vehicle, but to variable extent (inhibition percentage about 27.8-79.5\%) over time course studied (1-8 h) as compared with control. At the first $2 \mathrm{hrs}$ of the observation F1 chitosan gel showed $46.2 \%$ inhibition while F5 chitosan gel showed $25.8 \%$ inhibition. While after $8 \mathrm{hrs}$, the inhibitory effect was equal (79.5 and $51.3 \%$ ) for the same chitosan gel forms respectively. The rank order of edema inhibition using this method was in the following order F1 > F4 > F2 > F3 > F5. This order is similar to that appear in the percent of drug release. That means, there is a correlation between the percent of drug release from the various chitosan gel formulations and the antiinflammatory activity.

\section{Conclusion}

The results of in-vitro release, permeation and anti-inflammatory studies concluded that, a chitosan is a good carrier for quercetin as gel formulation. The polymer concentration and molecular weight of chitosan are very effective factors on the drug release percent of drug from gel formulations. Quercetin permeation through skin rat is independent on the viscosity of the gel. All gel formulations have significant antiinflammatory activity.

\section{REFERENCES}

1- A. W. Boots, G. R. Haenen and A. Bast, Eur. J. Pharmacol., 585, 325-330, (2008).

2- D. H. Lee, M. Szczepanski and Y. J. Lee, Biochem. Pharmacol., 75, 2345-2350 (2008).

3- W. M. Loke, J. M. Proudfoot, S. Stewart, A. J. McKinley, P. W. Needs, P. A. Kroon, J. M. Hodgson and K. D. Croft, ibid., 75, 1045-1050 (2008).

4- J. L. Lee, H. Mukhtar, D. R. Bickers, L. Kopelovich and M. Athar, "Cyclooxygenase in the skin: Pharmacological and toxocological implications" Toxicol. Appl. Pharmacol., 192, 294-06 (2003).

5- K. A. Khaled, Y. M. El-Sayed and B. M. Al-Hadiya, Drug Dev. Ind. Pharm., 29, 397-405 (2003).

6- M. R. Lauro, M. L. Torre, L. Maggi, F. De Simone, U. Conte and R. P. Aquino, ibid., 28, 371-378 (2002).

7- K. Azuma, K. Ippoushi, H. Ito, H. Higashio and J. Terao, J. Agric. Food Chem., 50 1706-1712, (2002).

8- D. Fasolo, L. Schwingel, M. Holzschuh, V. Bassani and H. Teixeira, J. Pharm. Biomed. Anal., 44, 1174-1180 (2007).

9- O. Felt, P. Furrer, J. M. Mayer, B. Plazonnet, P. Buri and R. Gurny, "Topical use of chitosan in ophthalmology : tolerance assessment and evaluation of precorneal retension", Int. J. Pharm., 180, 185-193 (1999).

10- S. Patashnik, L. Rabinovich and G. Golomb, "Preparation and evaluation of chitosan microspheres containing biphosphonate", J. Drug Target., 4, 371380, (1997).

11- J. S. Song, C. H. Such, Y. B. Park, S. H. Lee, N. C. Yoo, J. D. Lee, K. H. Kim and S. K. Lee, "A phase I/IIa study on intraarticular injection of holmium-166chitosan complex for the treatment of knee synovitis of rheumatoid arthritis", Eur. J. Nucl. Med., 28, 489-497 (2001).

12- R. A. A. Muzzarelli, "Human enzymatic activities related to the therapeutic administration of chitin derivatives", Cell Mol. Life Sci., 53, 131-140 (1997). 
13- D. Koga, In: R. Chen, H. C. Chen (Eds.), Chitin Enzymology Chitinase, Adv. Chitin Sci., 3, 16-23 (1998).

14- A. F. Kotze, H. L. Luessen, M. Thanou, J. C. Verhoef, A. G. de Boer, H. E. Junginger and C. M. Lehr, "Chitosan and Chitosan Derivatives as Absorption Enhancers for Peptide Drugs Across Mucosal Epithelia", In: E. Mathiowitz, D. E. Chickering III, C. M. Lehr (Eds.), Bioadhesive Drug Delivery Systems, Marcel Dekker Inc, New York, 1999, pp. 341-85.

15- I. A. Alsarra, "Chitosan topical gel formulation in the management of burn wounds", Int J. Bio. Macrom., 45, 16-21 (2009).

16- X. F. Liu, Y. L. Guan, D. Z. Yang, Z. Li and K. D. Yao, "Antibacterial action of chitosan and carboxymethylated chitosan", J. Appl. Polym. Sci., 79, 1324-1335 (2001).

17- M. G. Peter, "Application and environmental aspects of chitin and chitosan", J. Macromol. Sci., 32, 629- 640 (1995).

18- G. M. EL Maghraby, "Transdermal delivery of hydrocortisone from eucalyptus oil microemulsion: Effect of cosurfactant", Int. J. Pharm., 355, 285 292 (2008).

19- T. H. Tran, Y. Guo, D. Song, R. S. Bruno and X. Lu, J. Pharm. Sci., 103, 840-852 (2014).

20- J. Varshosaz, M. Tabbakhian and Z. Salmani, "Design of a thermosensitive chitosan/poloxamer in situ gel for ocular delivery of ciprofloxacin", Open. Drug Del. J., 2, 61-70 (2008).
21- S. A. AL-Suwayeh, "Transdermal delivery of isoradipine through excised rabbit skin effect of vehicle and drug concentration", Saudi Pharm. J., 11, 46-52 (2003).

22- Y. Wada, Y. Etoh, A. Ohira, H. Kimata, T. Koide, H. Ishihama and Y. Mizushima, "Percutaneous absorbtion and antiinflammatory activity of indomethacin in ointment", J. Pharm. Pharmcol., 34, 467468 (1982).

23- E. Escribano, A. C. Calpena, J. Queralt, R. Obach and J. Domenench, "Assessment of diclofenac permeation with different formulations: anti-inflammatory study of a selected formula", Eur. J. Pharm. Sci., 19, 203-210 (2003).

24- K. A. Walters and M. S. Roberts, "Veterinary Applications of Skin Penetration Enhancers", In: K. A. Walters, J. Hadgraft, Eds, Pharmaceutical Skin Penetration Enhancement. New York, NY: Marcel Dekker, 1993, p. 115.

25- J. Hilton, B. H. Woolen, R. C. Scott, T. R. Auton, K. L. Trebilock and M. F. Wilks, "Vehicle effects on the in-vitro precutaneous absorption through rate and human skin", Pharm. Res., 11, 1396-1400 (1994).

26- Y. Hiramatsu, S. Akita, P. A. Salamin and R. Maier, "Assessment of topical nonsteroidal anti-inflammatory drugs in animal models", Arznei Forrsch., 40, 1117- 1124 (1990). 


نشرة العلوم الصيدليـة 20

أداء الكورسيتين المحمل على هلاميات الكيتوزان كنظام لتوصيل الدواء الموضعي

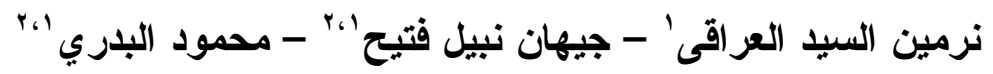

'قسم الصيدلانيات ، كلية الصيدلة ، جامعة أسيوط

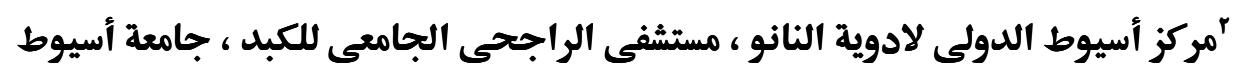

تم فى هذا البحث در اسة ملائمة الكيتوز ان كمادة حاملة للعقار ات فى أنظمة التوصيل الــدو ائى التى

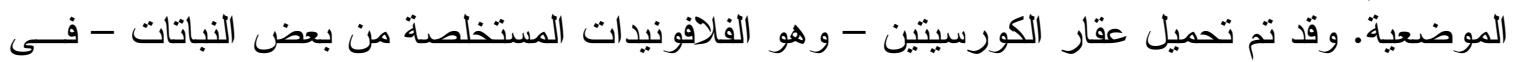

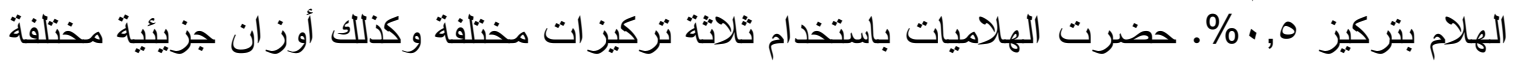

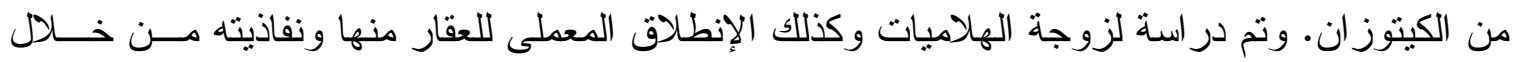

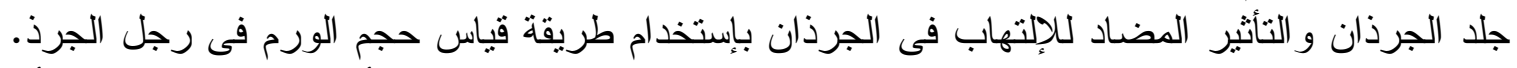

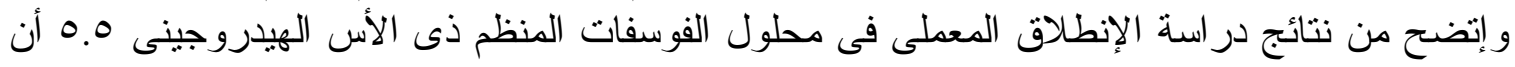

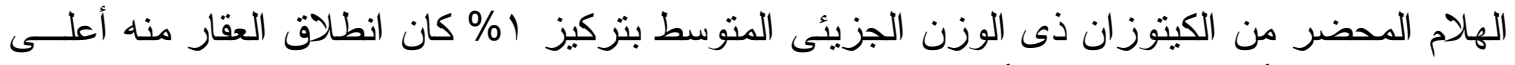

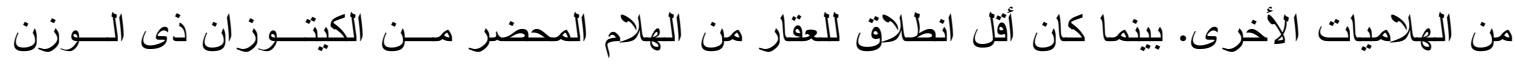

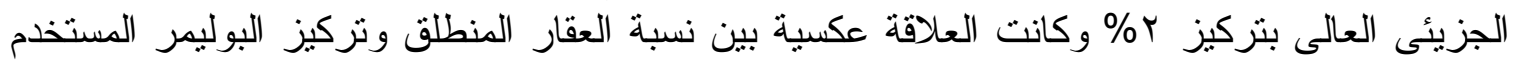

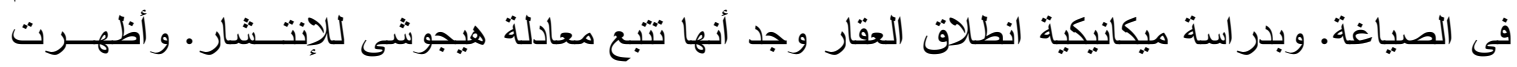

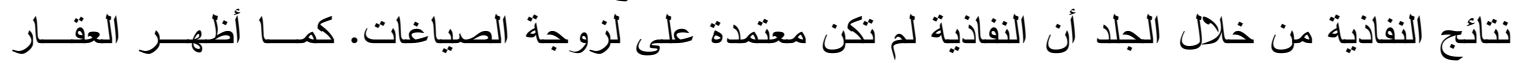

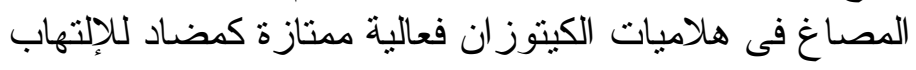

